\title{
AWARENESS AND KNOWLEDGE OF BREAST CANCER RISK FACTORS, SYMPTOMS AND SCREENING AMONG FEMALES IN A HOSPITAL IN NORTH INDIA
}

\author{
Mushood G. Nabi', Andleeb Ahangar2, Hanifa Akhtar ${ }^{3}$, Aftab Akbar', Syed Arshad Mustafa ${ }^{5}$ \\ ${ }_{1}^{1}$ Assistant Professor, Department of Radiotherapy, Government Medical College, Srinagar, Kashmir, India. \\ ${ }^{2}$ Consultant, Department of Ophthalmology, DHS, Srinagar, Kashmir, India. \\ ${ }^{3}$ Registrar, Department of Radiotherapy, Government Medical College, Srinagar, Kashmir, India. \\ ${ }^{4}$ Registrar, Department of General Surgery, Government Medical College, Srinagar, Kashmir, India. \\ ${ }_{5}^{5}$ Lecturer, Department of Radiotherapy, Government Medical College, Srinagar, Kashmir, India.
}

\begin{abstract}
BACKGROUND

Breast cancer is the second most common cancer in the world and by far the most frequent cancer among women with an estimated 1.67 million new cancer cases diagnosed in 2012. Breast cancer ranks as the fifth cause of death from cancer overall $(522,000$ deaths) and while it is the most frequent cause of cancer death in women in less developed regions $(324,000$ deaths $)$, it is now the second cause of cancer death in more developed regions after lung cancer.
\end{abstract}

AIM

To assess the awareness and knowledge about various risk factors, symptoms and screening methods of breast cancer.

\section{MATERIALS AND METHODS}

This descriptive cross-sectional study was conducted among 80 adult females. Data was collected using a self-administered questionnaire, which included questions on socio-demographic data, knowledge of various risk factors, symptoms and screening of breast cancer.

\section{RESULTS}

The mean age of participants was 39.25 years with $42.5 \%$ aged 31 to 40 years. Majority $60 \%$ participants had a poor knowledge about various risk factors of breast cancer. No participant could correctly identify all the seven symptoms mentioned in the questionnaire. Maximum of five symptoms of breast cancer were identified by only $17.5 \%$. Majority $60 \%$ participants had not heard about Breast Self-Examination (BSE), only 5\% participants had heard about BSE and were regular performers. None of the participants had clinical breast examination in the past year and only $7.5 \%$ participants had heard of mammography.

\section{CONCLUSION}

The present study points to the insufficient knowledge of female participants about various risk factors and symptoms of breast cancer. Knowledge about Breast Self-Examination, clinical breast examination and mammography was also not satisfactory.

\section{KEYWORDS}

Breast Cancer, Risk Factors, Symptoms, Breast Self-Examination, Mammography.

HOW TO CITE THIS ARTICLE: Nabi MG, Ahangar A, Akhtar H, et al. Awareness and knowledge of breast cancer risk factors, symptoms and screening among females in a hospital in North India. J. Evolution Med. Dent. Sci. 2016;5(32):1719-1724, DOI: $10.14260 /$ jemds/2016/406

\section{INTRODUCTION}

An estimated 14.1 million new cancer cases and 8.2 million cancer deaths occurred in 2012 worldwide. Breast cancer is the second most common cancer in the world and by far the most frequent cancer among women with an estimated 1.67 million new cancer cases diagnosed in 2012 (25\% of all cancers). A slightly majority of cases occur in women in less developed region $(883,000$ cases) than more developed regions $(794,000)$. Incidence rates vary nearly fourfold across the world regions with rates ranging from 27 per 100,000 in middle Africa and Eastern Asia to 96 in Western Europe.

Financial or Other, Competing Interest: None.

Submission 17-03-2016, Peer Review 02-04-2016,

Acceptance 05-04-2016, Published 20-04-2016.

Corresponding Author:

Dr. Mushood G. Nabi,

Post Box Number 23,

General Post Office GPO,

Srinagar-190001,

Kashmir, India.

E-mail: mushoodnabi@yahoo.co.in

DOI: $10.14260 /$ jemds/2016/406
Breast cancer ranks as the fifth cause of death from cancer overall (522,000 deaths) and while it is the most frequent cause of cancer death in women in less developed regions $(324,000$ deaths $14.3 \%$ of total), it is now the second cause of cancer death in more developed regions $(198,000$ deaths $15.4 \%$ ) after lung cancer. The range in mortality rates between world regions is less than that for incidence because of more favourable survival from breast cancer in (High incidence) developed regions.[1]

India is a subcontinent with wide ethnic, cultural, religious and economic diversity. With rising incidence and awareness, breast cancer is the commonest cancer in urban Indian females and the second commonest in the rural Indian women. As per ICMR-PBCR data, breast cancer is the commonest cancer among women in urban registries of Delhi, Mumbai, Ahmadabad, Calcutta and Trivandrum, where it constitutes $>30 \%$ of all cancers in females. In the rural population based cancer registry of Barshi, breast cancer is the second commonest cancer in women after cancer of uterine cervix.[2]

Breast cancer has been reported to occur a decade earlier in Indian patients compared to their western counterparts. 
While the majority of breast cancer patients in western countries are postmenopausal and in their 60s and 70s; the picture is quite different in India with premenopausal patients constituting about $50 \%$ of all patients. More than $80 \%$ of Indian patients are younger than 60 years of age. The average age of breast cancer patients has been reported to be $50-53$ years in various population based studies done in different parts of the country.[2]

The causes of the breast cancer are not fully known. However, researchers have identified a number of factors that increase ones chance of getting breast cancer. These are called "risk factors." Risk factors do not cause breast cancer, but can increase the chances of getting breast cancer. Established risk factors for breast cancer includes family history of breast cancer, gender, early menarche ( $<12$ years), late menopause ( $>55$ years), no breast feeding, oral contraceptive pills, aging, alcohol, smoking, late age at full term pregnancy ( $>30$ years), obesity, high dose radiation to chest and personal history of breast cancer.[3,4]

For primary prevention, it is very important that every woman is adequately made aware of various risk factors and symptoms of breast carcinoma. Early detection of breast carcinoma can be achieved by performing Breast SelfExamination (BSE), Clinical Breast Examination (CBE) and mammography. The practice of breast self-examination may have great value in terms of awareness and motivating women to see a health care provider when they find a lump. ${ }^{[5]}$ The purpose of present study was to assess the basic knowledge of various risk factors of breast carcinoma and its symptoms. Awareness about Breast Self-Examination (BSE), Clinical Breast Examination (CBE) and mammography among the study participants was also assessed.

\section{MATERIALS AND METHODS}

The present descriptive cross-sectional study was carried out from September 2015 to November 2015. The study population consisted of women attendants who attended various outpatient and inpatient departments of our Medical College Hospital during this period and consented for participation in the study after prior explaining the nature and objectives of the present study. A total of 80 women consented for participation in the present study. Data was collected by means of a structured questionnaire devised by the authors themselves. Besides English the questionnaire was also available in Urdu language. Willingness to participate in the present study was obtained by means of written informed consent. The participants were requested to fill out the questionnaire in presence of the female authors of the study, so as to clarify doubts if any.

The questionnaire sought information about sociodemographic status including age, marital status, residence, level of education, occupation, family history of any cancer including breast cancer and monthly income of the participants. The questionnaire aimed to know about the knowledge of various risk factors and symptoms of breast cancer. The level of knowledge of risk factors was assessed by categorizing into four groups. "Excellent" knowledge group were those who answered $80-100 \%$ correct answers (12-15) about breast cancer risk factors, "very good" knowledge group were those who answered $60-79 \%$ correct answers (9-11), "Good" knowledge group were those who answered 40-59\% correct answers (6-8) and participants who answered less than $40 \%$ correct answers (0-5) were "Poor" knowledge group. Further the questionnaire was also aimed to assess the awareness of participants about Breast Self-Examination (BSE), Clinical Breast Examination (CBE) and Mammography. Upon completion of the questionnaire, an interactive session followed with the participants in which information regarding breast cancer risk factors, symptoms and screening procedures were discussed. Pamphlets regarding correct methods of breast self-examination were also distributed.

Attendants presenting with signs and symptoms suggestive of any breast disease and women with any patient of carcinoma breast in immediate family were excluded from the study.

\section{The data of all the Participants was compiled and assessed} for:

1. Awareness and level of knowledge about various risk factors of breast cancer.

2. Awareness and knowledge of symptoms of breast cancer.

3. Awareness about Breast self-examination, clinical breast examination and mammography among the study participants.

\section{RESULTS}

A total of 80 women participated in the present study. The youngest participant was 21 years old and the oldest was 60 years old. The mean age was 39.25 years. The majority 34 (42.5\%) were of 31-40 years' age group followed by 22 (27.5\%) of $41-50$ years. Eighteen $(22.5 \%)$ participants belonged to 21-30 years' age group, whereas only $6(7.5 \%)$ belonged to 51-60 years' age group. The socio-demographic characteristics of study participants are shown in Table 1. Majority 72 (90\%) of the study participants were married, only $8(10 \%)$ participants were unmarried. Majority 42 (52.5\%) of the study participants belonged to urban setting, whereas $38(47.5 \%)$ belonged to rural areas. Majority 76 (95\%) of the study participants followed the Muslim faith, only $2(2.5 \%)$ each of our study participants were Hindus and Sikhs. On enquiring about the educational status, 42 (52.5\%) of our study participants were illiterate, $4(5 \%)$ had primary education, $10(12.5 \%)$ had secondary education, $2(2.5 \%)$ had attended colleges, $16(20 \%)$ were graduates, whereas 6 $(7.5 \%)$ were post graduates. The majority $56(70 \%)$ of our study participants were housewives, 14 (17.5\%) were employed in government sector, $6(7.5 \%)$ had private jobs, whereas 4 (5\%) were unemployed. About 42 (52.5\%) of our participants had a monthly income of 5000-10,000 rupees, whereas 16 (20\%) had a monthly income of 10,000-30,000 rupees, $14(17.5 \%)$ had a monthly income of $30,000-50,000$ rupees and $8(10 \%)$ had a monthly income of $<5000$ rupees.

Regarding overall assessment of level of knowledge about various risk factors of cancer breast, our results concluded that $60 \%$ of study participants had a "poor" knowledge, whereas $22.5 \%$ had a "good" knowledge and only $17.5 \%$ had "very good" knowledge about various risk factors of cancer breast. No participant had an "excellent" knowledge about the risk factors of the cancer breast (Table 2). Only 6 (7.5\%) participants were aware of a maximum of ten risk factors, whereas $4(5 \%)$ participants were not aware of any risk factor involving cancer breast.

The most identified risk factor was smoking 54 (67.5\%), followed by obesity 52 (65\%), whereas the least identified risk 
factor was late menopause $>54$ years in $6(7.5 \%)$ participants (Table 3). About $60 \%$ participants were of the opinion that older age 55+ was a risk factor for cancer breast, whereas $57.55 \%$ participants were aware that female gender is a risk factor for cancer breast. Short period of breast feeding was identified as a risk factor by only 38 (47.5\%) participants, similarly only $34(42.5 \%)$ and $32(40 \%)$ participants correlated a positive family history and genetic factors as risk factors for cancer breast. Majority of about 72 (90\%) participants did not agree early menarche $<12$ years, radiation exposure to chest and age at first birth $>30$ years to be a risk factor. Similarly, 66 (82.5\%) participants did not agree with null parity and personal history of breast cancer to be a risk factor for cancer breast. Consumption of oral contraceptive pills and alcohol by females was also not considered as a risk factor by $60(75 \%)$ and $58(72.5 \%)$ participants respectively.

When we compared the level of knowledge about risk factors of cancer breast with the level of education among various participants, we found that $95.2 \%$ illiterate participants had "poor" knowledge of risk factors, whereas no participant of college, graduate and post graduate educational level had "poor" knowledge (Table 4), similarly no illiterate participant had a "very good" level of knowledge of risk factors, whereas $100 \%$ of participants who had been to college, $50 \%$ of graduated and $66.6 \%$ of post graduates had "very good" level of knowledge about risk factors of cancer breast. The sources of information about breast cancer risk factors were mainly from family/friends and relatives in 24 (30\%) participants followed by television in $18(22.5 \%)$.

When the participants were asked about symptoms of breast cancer, the most identified symptom was palpable lump/thickening in the breast in $64(80 \%)$ followed by changes in shape and size of breast in 42 (52.5\%). Sore/ulceration in breast that does not heal was identified as a symptom by $38(47.5 \%)$ and blood stained discharge from nipple was identified as a symptom of breast cancer by 36 (45\%) participants. The other less identified symptoms were redness, warmth or darkening of skin 18 (22.5\%), lump in armpit $12(15 \%)$ and dimpling or puckering of skin or nipple $10(12.5 \%)$ (Table 5).

No participant could correctly identify all the seven symptoms mentioned in the questionnaire. Maximum of five symptoms of breast cancer were correctly identified by only $14(17.5 \%)$ participants followed by four symptoms identified by $10(12.5 \%)$. About $18(22.5 \%)$ participants were able to identify correctly one and three symptoms of breast cancer. Majority of 20 (25\%) participants were able to identify two symptoms correctly of breast cancer.

When asked about Breast self-examination, 48 (60\%) participants had not heard about BSE, $18(22.5 \%)$ had heard but were irregular performers, $10(12.5 \%)$ had heard but did not perform BSE at all, whereas only 4 (5\%) participants had heard about BSE and were regular performers (Figure 1).

The most common reason for non-performance of BSE was "not knowing the correct method" in $57.14 \%$ and being "too busy" was the second most important reason for nonperformance in $42.8 \%$ participants. The main source of information about BSE was Television in $25 \%$ followed by family, friends/relatives, Health care professionals and internet in $18.75 \%$. None of the participants had clinical breast examination in the past year, the main reason cited was "lack of proper knowledge" and "non-awareness" about CBE. When asked about Mammography, only 6 (7.5\%) participants were aware of mammography. The source of knowledge about mammography was television in $33.3 \%$, health care professionals in $33.3 \%$ and internet in $33.3 \%$ participants.

When participants were asked about treatment of breast cancer, single modality treatment in the form of surgery, chemotherapy, radiotherapy was answered by $22(27.5 \%), 12$ $(15 \%)$ and $6(7.5 \%)$ participants, whereas $22(27.5 \%)$ participants knew about dual modality of surgery and chemotherapy as the treatment of cancer breast. Only 6 (7.5\%) knew a combination of surgery, chemotherapy and radiotherapy as the treatment of breast cancer and 12 (15\%) participants had no idea of the treatment of breast carcinoma.

\begin{tabular}{|c|c|c|}
\hline Characteristics & Number (80) & Percentage \\
\hline \multicolumn{3}{|l|}{ Age (Years) } \\
\hline $21-30$ & 18 & 22.5 \\
\hline $31-40$ & 34 & 42.5 \\
\hline $41-50$ & 22 & 27.5 \\
\hline $51-60$ & 6 & 7.5 \\
\hline \multicolumn{3}{|l|}{ Marital Status } \\
\hline Married & 72 & 90 \\
\hline Unmarried & 8 & 10 \\
\hline \multicolumn{3}{|l|}{ Place of Residence } \\
\hline Urban & 42 & 52.5 \\
\hline Rural & 38 & 47.5 \\
\hline \multicolumn{3}{|l|}{ Education } \\
\hline Illiterate & 42 & 52.5 \\
\hline Primary & 4 & 5 \\
\hline Secondary & 10 & 12.5 \\
\hline College & 2 & 2.5 \\
\hline Graduate & 16 & 20 \\
\hline Post Graduate & 6 & 7.5 \\
\hline \multicolumn{3}{|l|}{ Occupation } \\
\hline House wife & 56 & 70 \\
\hline Government job & 14 & 17.5 \\
\hline Private job & 6 & 7.5 \\
\hline Unemployed & 4 & 5 \\
\hline $\begin{array}{r}\text { Table } 1 \\
\text { Characteri }\end{array}$ & $\begin{array}{l}\text { cio-Demograp } \\
\text { s of Study Popu }\end{array}$ & \\
\hline
\end{tabular}

\begin{tabular}{|c|c|c|}
\hline $\begin{array}{c}\text { Level of } \\
\text { Knowledge }\end{array}$ & $\begin{array}{c}\text { Number of Risk } \\
\text { Factors Identified }\end{array}$ & $\begin{array}{c}\text { Number } \\
\text { (\% Age) }\end{array}$ \\
\hline $\begin{array}{c}\text { Excellent } \\
(80-100 \%)\end{array}$ & $12-15$ & $0(0 \%)$ \\
\hline $\begin{array}{c}\text { Very Good } \\
(60-79 \%)\end{array}$ & $9-11$ & $14(17.5 \%)$ \\
\hline $\begin{array}{c}\text { Good } \\
(40-59 \%)\end{array}$ & $6-8$ & $18(22.5 \%)$ \\
\hline Poor (<40\%) & $0-5$ & $48(60 \%)$ \\
\hline \multicolumn{2}{|c|}{ Table 2: Level of Knowledge about Various Risk } \\
Factors of Breast Carcinoma \\
\hline
\end{tabular}




\begin{tabular}{|c|c|c|}
\hline $\begin{array}{c}\text { Risk } \\
\text { Factors }\end{array}$ & $\begin{array}{c}\text { True N } \\
(\%)\end{array}$ & $\begin{array}{c}\text { False N } \\
(\%)\end{array}$ \\
\hline Family history & $34(42.5)$ & $46(57.5)$ \\
\hline Alcohol & $22(27.5)$ & $58(72.5)$ \\
\hline Oral contraceptives & $20(25)$ & $60(75)$ \\
\hline Genetic factors & $32(40)$ & $48(60)$ \\
\hline Smoking & $54(67.5)$ & $26(32.5)$ \\
\hline Being women & $46(57.5)$ & $34(42.5)$ \\
\hline Age $55+$ & $48(60)$ & $32(40)$ \\
\hline Age at first birth $>30$ years & $8(10)$ & $72(90)$ \\
\hline Short period of breast feeding & $38(47.5)$ & $42(52.5)$ \\
\hline Early menarche $<12$ years & $8(10)$ & $72(90)$ \\
\hline Late menopause $>54$ years & $6(7.5)$ & $74(92.5)$ \\
\hline Obesity & $52(65)$ & $28(35)$ \\
\hline Radiation exposure & $8(10)$ & $72(90)$ \\
\hline Null parity & $14(17.5)$ & $66(82.5)$ \\
\hline $\begin{array}{l}\text { Personal history of cancer } \\
\text { breast }\end{array}$ & $14(17.5)$ & $66(82.5)$ \\
\hline \multicolumn{3}{|l|}{ Table 3: Knowledge a } \\
\hline
\end{tabular}

\begin{tabular}{|c|c|c|c|c|c|}
\hline $\begin{array}{c}\text { Level of } \\
\text { Education }\end{array}$ & $\begin{array}{c}\text { Excellent } \\
\text { (\%) }\end{array}$ & $\begin{array}{c}\text { Very } \\
\text { Good } \\
(\%)\end{array}$ & $\begin{array}{l}\text { Good } \\
(\%)\end{array}$ & $\begin{array}{l}\text { Poor } \\
(\%)\end{array}$ & $\begin{array}{c}\text { Total } \\
\text { (\%) }\end{array}$ \\
\hline Illiterate & - & - & $\begin{array}{c}2 \\
(4.76) \\
\end{array}$ & $\begin{array}{c}40 \\
(95.2) \\
\end{array}$ & $\begin{array}{c}42 \\
(100) \\
\end{array}$ \\
\hline $\begin{array}{c}\text { Primary } \\
\text { School }\end{array}$ & - & - & $2(50)$ & $2(50)$ & $\begin{array}{c}4 \\
(100)\end{array}$ \\
\hline $\begin{array}{l}\text { Secondary } \\
\text { School }\end{array}$ & - & - & $4(40)$ & $6(60)$ & $\begin{array}{c}10 \\
(100) \\
\end{array}$ \\
\hline College & - & $2(100)$ & - & - & $\begin{array}{c}2 \\
(100)\end{array}$ \\
\hline Graduate & - & $\begin{array}{c}8 \\
(50 \%)\end{array}$ & $8(50)$ & - & $\begin{array}{c}16 \\
(100)\end{array}$ \\
\hline $\begin{array}{c}\text { Post } \\
\text { Graduate }\end{array}$ & - & $\begin{array}{c}4 \\
(66.6)\end{array}$ & $\begin{array}{c}2 \\
(33.3)\end{array}$ & - & $\begin{array}{c}6 \\
(100)\end{array}$ \\
\hline
\end{tabular}

\begin{tabular}{|c|c|}
\hline Symptoms & N (\%) \\
\hline Breast lump/Thickening & $64(80)$ \\
\hline Blood stained nipple discharge & $36(45)$ \\
\hline $\begin{array}{c}\text { Sore/ulceration in breast that does not } \\
\text { heal }\end{array}$ & $38(47.5)$ \\
\hline Lump in armpit & $12(15)$ \\
\hline $\begin{array}{c}\text { Changes in breast shape and size } \\
\text { nipple }\end{array}$ & $42(52.5)$ \\
\hline $\begin{array}{c}\text { Dimpling or puckering of skin of breast or } \\
\text { Redness, warmth or darkening }\end{array}$ & $10(12.5)$ \\
\hline \multicolumn{2}{|c|}{$18(22.5)$} \\
\hline
\end{tabular}

\begin{tabular}{|c|c|c|c|}
\hline $\begin{array}{c}\text { Source of } \\
\text { Knowledge }\end{array}$ & $\begin{array}{c}\text { BSE } \\
\text { N (\%) }\end{array}$ & $\begin{array}{c}\text { Mammography } \\
\text { N (\%) }\end{array}$ & $\begin{array}{c}\text { Risk } \\
\text { Factors } \\
\text { N (\%) }\end{array}$ \\
\hline $\begin{array}{c}\text { Family, } \\
\text { Friends, } \\
\text { Relatives }\end{array}$ & $6(18.75)$ & - & $24(30)$ \\
\hline $\begin{array}{c}\text { Health care } \\
\text { professionals }\end{array}$ & $6(18.75)$ & $2(33.33)$ & $14(17.5)$ \\
\hline Television & $8(25)$ & $2(33.33)$ & $18(22.5)$ \\
\hline Internet & $6(18.75)$ & $2(33.33)$ & $6(7.5)$ \\
\hline $\begin{array}{c}\text { Newspaper/m } \\
\text { agazine/books }\end{array}$ & $2(6.25)$ & - & $2(2.5)$ \\
\hline Radio & $4(12.5)$ & - & $10(12.5)$ \\
\hline $\begin{array}{c}\text { Do not } \\
\text { remember }\end{array}$ & - & - & $6(7.5)$ \\
\hline \multicolumn{2}{|c|}{ Table 6: Main Source of Knowledge } \\
\hline
\end{tabular}

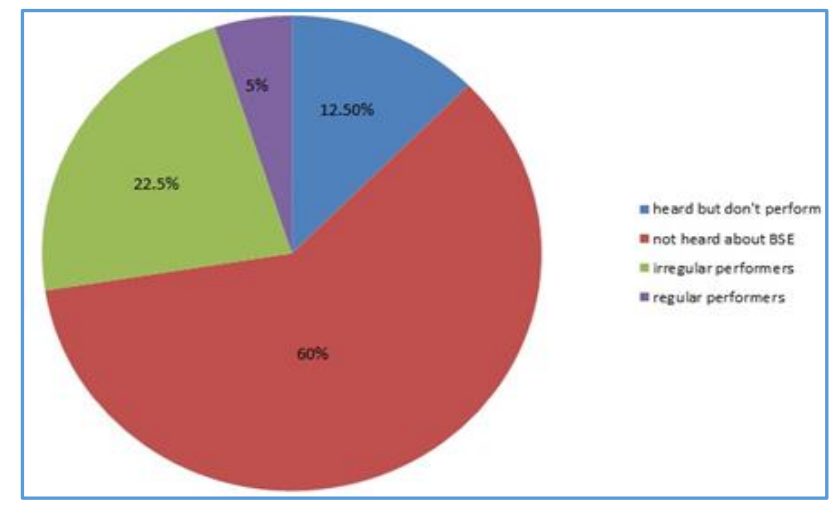

Fig. 1: Breast Self-Examination

\section{DISCUSSION}

Breast cancer is by far the most frequent cancer among women. Lung cancer is now the leading cause of cancer death among women in more developed regions $(210,000$ deaths $)$ followed by breast cancer $(198,000$ deaths), which ranks as most frequent in women in less developed regions $(324,000$ deaths), followed by cancer of lung (281,000 deaths) and cervix (230,000 deaths).[1] Keeping into view huge mortality because of cancer breast among women, it is very important that females be aware of various risk factors and symptoms of the disease. In the present study, our results revealed that $60 \%$ participants had a poor knowledge about various risk factors of cancer breast. Study by TT Amin et al.[6] on adult Saudi women also reported low overall level of knowledge regarding breast cancer risk factors. Patel NA et al.[7] in a study in urban slums of Turbhe, Navi Mumbai, found no knowledge about breast cancer risk factors in $93.1 \%$ participants.

In a study on female secondary school teachers in Selangor Malaysia, Parsa et al.[8] found knowledge about risk factors of cancer breast in only 55\% participants, whereas in a study among female health workers in a Nigerian Urban City Akhibge AO et al.[9] found that $55 \%$ participants had a poor knowledge about the risk factors of breast cancer. In our study participants showed poor understanding of various breast cancer risk factors as majority of the respondents did not know that the following to be risk factors of breast cancer: Alcohol consumption, Oral contraceptive use, Null parity, Short duration of breast feeding, Personal history of breast cancer, Genetic factors, Early menarche $<12$ years, Radiation exposure, Age at first birth $>30$ years, Late menopause $>54$ years.

Al Dubai SAR et al.[4] in a study among Malaysian women living in Shah Alam City also found that the knowledge on risk factors of breast cancer was unsatisfying as most of the respondents did not know the following to be risk factors of breast cancer: Null parity, Delivery at more than 30 years old, Shorter duration of breast feeding, Oral contraceptive pills, Menopause after age of 50 and Menarche before age of 11 years. Similarly Ahmed AS et al.[5] in a study on Saudi women aged from twenty to above sixty years found that most of the participants in their study did not know the association between breast cancer and short periods of breast feeding, early menarche, late menopause and delivery of first child after age of 30 years.

In a study by Parsa et al.[8] only $13 \%$ and $18.9 \%$ respondents knew about the relationship between late age of menopause and early menarche with breast cancer 
respectively. In our study, the most identified risk factor was smoking (67.5\%). Similar results were found by Ahmed AS et al.[5] also who reported smoking as the most identified risk factor in $69.11 \%$ participants.

Women who have early age at menarche $(<12$ years $)$ have a $30 \%$ increased risk of breast cancer, while those who have a later age of menopause ( $>60$ years) will have a $20-50 \%$ increased risk of disease. Women who have never had children or those who are more than 30 years at the time of their first child's birth are twice as likely to develop breast cancer than women who had their first child before the age of 30 years. [10] Recognizing the symptoms of breast cancer is essential for early self-detection and treatment of breast cancer.[10] In the present study, $80 \%$ of the studied population knew that a breast lump/thickening could be a warning sign of breast cancer.

Our results are similar to studies done by Ahmed AS et al.[5] and Al Dubai SAR et al.[4] who reported breast lump as the main identified symptom in $92.5 \%$ and $90.8 \%$ respectively. In some studies like Patel NA et al.[7] and Sharma PK et al.[11] breast lump was identified as a symptom of breast carcinoma by only $19.36 \%$ and $21.37 \%$ participants. In our study only $15 \%$ participants knew that lump in armpit can also be a symptom of breast cancer; however, Al Dubai SAR et al. ${ }^{[4]}$ in a study reported $75.2 \%$ participants having knowledge of enlargement of neighbouring lymph nodes as a symptom of breast cancer.

It is thought that Breast Self-Examination (BSE) makes women more breast aware, which in turn may lead to an earlier diagnosis of breast cancer.[3] In our study $60 \%$ participants had not heard of breast self-examination and only $5 \%$ participants were regular performers of breast selfexamination. In a study by Sharma PK et al.[11] only $4.58 \%$ participants were aware of and periodically conducted breast self-examination, whereas in another study by Patel NA et al.[7] only 8 women out of 160 knew about breast self-examination among which only 2 women practiced breast self-examination. In our study the most common reason cited for nonperformance of breast self-examination was "not knowing the correct method" in $57.14 \%$ and being "too busy" was the second most common reason for non-performance in $42.85 \%$ participants. Similar findings were reported by Ahuja S et al.[12] also.

In our study, none of the participants had a clinical breast examination done in the past year. Similar results were reported by Sharma PK et al.[11] Lack of proper knowledge and non-awareness about CBE was the main reason cited for nonperformance. With regards to mammography awareness, only $7.5 \%$ participants in our study had heard about mammography. Our results are comparable to study by Montazeri A et al.[13] who in a population based survey in Tehran Iran reported 9\% participants having heard of mammography. However, in other studies like Al Dubai SAR et al. $\left.{ }^{4}\right] 50 \%$ of women were aware of mammography, similarly the importance of mammography for early detection of breast cancer was identified by $62.3 \%$ participants in a study conducted on Saudi Arabian women by Ahmed AS et al.[5]

The most important source of information about breast cancer risk factors in our study was interaction with members of family, friends and relatives (30\%). Television being readily available now a days was the second most important source of information (22.5\%) (Table 6) followed by health care professionals who were the third most common source of information (17.5\%) regarding breast cancer risk factors. Television was also the most common source of knowledge regarding breast self-examination (25\%). Internet was the second most common source of knowledge (18.75\%) regarding breast self-examination along with family, friends, relatives and health care professionals (Table 6).

\section{CONCLUSION}

The present study points to the insufficient knowledge of female participants about various risk factors and symptoms of breast cancer. Knowledge about breast self-examination, clinical breast examination and mammography was also not satisfactory and accordingly relevant educational programs and campaigns based on national level are needed to improve the knowledge level of women regarding breast cancer. The conservative nature of our society still prevents women from directly discussing sensitive issues with their health care providers, therefore there is a vital need to educate the female members of society to overcome knowledge deficits. Since this study is limited by its small sample size, studies with larger and representative samples are recommended to confirm the findings of the present study.

\section{REFERENCES}

1. Ferlay J, Soerjomataram I, Dixit R, et al. Cancer incidence and mortality worldwide: sources, methods and major patterns in GLOBOCAN 2012. Int J Cancer 2015;136(5):359-86.

2. Agarwal G, Ramakant P. Breast cancer care in India the current scenario and the challenges for the future. Breast care 2008;3(1):21-7.

3. Dellie ST, Neguse TM, Demissie M, et al. Knowledge about breast cancer risk factors, breast screening method and practice of breast screening among female health care professionals working in government hospitals, aaddis ababa, Ethiopia. IOSR Journal of pharmacy and biological sciences 2012;2(1):05-12.

4. Al Dubai SAR, Qureshi AM, Ali RS, et al. Awareness and knowledge of breast cancer and mammography among a group of Malaysian women in shah alam. Asian Pac J Cancer Prev 2011;12(10):2531-8.

5. Ahmed AS, Rehab M, Gharabawy El, et al. Knowledge, attitude and practice about breast cancer among women in saudi Arabia. Int arch med 2015;8:1-13.

6. Amin TT, Al Mulhim ARS, Al Meqihwi A. Breast cancer knowledge, risk factors and screening among adult saudi women in a primary health care setting. Asian Pac J Cancer Prev 2009;10(1):133-8.

7. Patel NA, Pandit D, Khantolkar A, et al. A study on awareness of breast carcinoma among the women aged 15 years and above in urban slums of turbhe, navi Mumbai. J Res Med Den Sci 2014;2(1):14-9.

8. Parsa P, Kandiah M, Mohd Zulkefli NA, et al. Knowledge and behavior regarding breast cancer screening among female teachers in selangor, Malaysia. Asian Pac J Cancer Prev 2008;9(2):221-7.

9. Akhigbe AO, Omuemu VO. Knowledge, attitude and practice of breast cancer screening among female health workers in a Nigerian urban city. BMC Cancer 2009;9:203. 
10. Yadav R, Chauhan $\mathrm{P}$, Kumar $\mathrm{S}$, et al. Comparative evaluation of breast cancer awareness in population in Haryana. Int J Sci Nature 2013;4(4):633-8.

11. Sharma PK, Ganguly E, Nagda D, et al. Knowledge, attitude and preventive practices of south Indian women towards breast cancer. The Health Agenda 2013;1(1):1622.
12. Ahuja S, Chakrabarti N. To determine the level of knowledge regarding breast cancer screening practices among a group of women in a tertiary care hospital in Mumbai, India. The Internet Journal of public health 2009;1(1).

13. Montazeri A, Vahdaninia M, Harirchi I, et al. Breast cancer in Iran: need for greater women awareness of warning signs and effective screening methods. Asia Pac Family Med 2008;7(1):6. 